\title{
The Role of Parental SES in Career Development of Children with Mild Intellectual Disabilities at Tinashe Vocational Rehabilitation and Training Centre, Zambia.
}

\author{
Mathatha Viola*, Ndhlovu Daniel \\ Zambia \\ *Corresponding Author: Mathatha Viola, Zambia

\begin{abstract}
The phenomenological study sought to establish the role of parental socio-economic status (SES) in the career development of their children with mild intellectual disabilities in Ndola, Zambia. The study used semi-structured interviews on a purposively selected sample of 10 parents ( 5 females and 5 males). Data was analysed thematically. Findings revealed that the SES of parents plays a role in the career development of their children with mild intellectual disabilities through role modeling and supporting children in careers. Based on these findings, the study recommends that the Ministry of Higher Education, through the skill training institution, sensitises parents on mild intellectual disabilities for them parents to gain an understanding of the educational implications of their children with mild intellectual disabilities. In addition, the Skill Training Institution should help form or strengthen Support Network Systems for parents of children with mild intellectual disabilities.
\end{abstract}

Keywords: Career Development, Intellectual Disability, Parent, Socioeconomic Status

(SES)

\section{BACKGROUND}

Parents are one of the most influential elements in the lives of their children. They have the ability to shape, sustain and develop children who will be interested, creative, tolerant.The concept of parents having an impact on their children's career development has been demonstrated empirically in the career development literature(Kerka, 2000;Whiston\& Keller, 2008; Faisal, 2014; Jamabo, 2014), among others.Recent research indicatesthat there are links between parental SES and career developmentof adolescents without disabilities (Ngozi \& Eze, 2015), however, nothing seems to indicate how theSESof parents plays a role in the career development of their children with mild intellectual disabilities. Based on this, the study sought to determine how the SES of parents plays a role in the career development of their children with mild intellectual disabilities.

\subsection{Statement of the Problem}

It has long been recognized that parental SES leads to high academic achievement of children (Kibera 2012; Jamabo, 2014; Faisal, 2014) and it is linked to career development. While this may hold true for children without disabilities, there is limited research on how theSES of parents plays a role in career development of their children with mild intellectual disabilities. Ignoring such a field would worsen the already existing discrimination of such childrenand exacerbate their unemployment rates. This study therefore sought to fill this gap.

\subsection{Purpose}

The purpose was to establish how parentalSES plays a role in the career development ofchildren with mild intellectual disabilities.

\subsubsection{Research Objectives}

- To establish how the socioeconomic status of parents plays a role in the career development oftheir children with mild intellectual disabilities.

\subsubsection{Research Questions}

- How does the socioeconomic status of parents play a role in the career development oftheir children with mild intellectual disabilities? 


\subsection{Theoretical Framework}

The Ecological Systems Theory by Urie Bronfenbrenner (1999) guided the study. The theory believes that career development is best understood by examining ones' context (environment) and it depends on the heterogeneity of an individual. Itbelieves that a person's ability to reach their potential is dependent on the presence of real life opportunities and situations in the environment (Roundy, 2015). The ecological theory argues that individuals better adjust and are more satisfied in environments that match their attitudes, values, goals and experiences, that is, they are more satisfied when there is a fit between themselves and their environment (Schultheiss, Kress, Manzi\& Glasscock, 2001). The theory helped understand how the SES of parents plays a role in the career development of children with mild intellectual disabilities.

\subsection{Significance of the Study}

Findings may contribute to the knowledge gap on howthe SESof parents plays a role in the career development of their children with mild intellectual disabilities.

\section{LiTERATURE REVIEW}

Elshelman (2013) conducted a study to examine the SES and perceived social class as predictors of career adaptability and educational aspiration in a sample of American high school students. SES was measured using caregivers' occupation and education and the MacArthur Scale of Subjective Social Class-Youth Version (Goodman et al., 2001) assessed subjective social class. Career Adaptability was measured by the Career Futures Inventory-Revised (CFI-R) (Rottinghaws, Buelow, Matyja and Schneider, 2012) and the Career Maturity Inventory CMI) form C (Savikas\&Porfeli, 2011). Data was analysed using hierarchical multiple regression. SES and perceived social class independently predicted educational aspirations and expectations while SES independently predicted occupational aspirations and expectations. The study represents a step towards developing empirically informed vocational intervention that takesSES and social class into account. The 2013 study differs with the current in its methodology, context and focus.

Faisal (2014) conducted a study on the influence of parental SES on their involvement at home among Jordanian parents who had enrolled their children in government schools in Jordan. A total sample of 156 children who completed their (Tawjechi) education at government schools was selected usingpurposive convenient sampling. Questionnaires were used to collect data. Results revealed that the education level has greater impact on the SES parental involvement strategies. In addition, parental income and occupation influence parental SESand consequently parental involvement and finally career choices. The study recommends that family care agencies, educational institutions, social work agencies and interventions are important in helping children have better lives. On the contrary, the present qualitative study looks at how the SES of parents plays a role in the career development of their children with mild intellectual disabilities.

Ramona and Loredana (2014) conducted a study on the impact of the family on the career choices of adolescents in Romania. The sample consisted of 60 pupils from the final grade. The study used a test portfolio: Parent Career Behaviour Checklist (Keller \&Whist on, 2008); EMBU questionnaires (Perris et al., 1980), Adult Attachment Scale (Collins \& Read, 1990). Results showed that parental income influence career decision and career making process. The 2014quantitative study was designed to identify variables from the family environment while the current qualitative study uses the identified parental factor, SES, to ascertain how it plays a role in the career development of children with mild intellectual disabilities.

Gabriel, Muasya, Mwangi, Makhungulu and Ewoi (2016) used a descriptive study to investigate how parental SES and involvement in students' learning activities can influence children's academic achievement in selected schools in urban informal settlements of Westlands Division in Nairobi County, Kenya. The study was permised on the Classical Liberal Theory of Equal Opportunity and Social Darwinism proposed by Charles Darwin. A sample of 125 respondents (91 students, 18 teachers and 16 parents) was used. Questionnaires were used to collect data from students. Focus Group Discussions were used for teachers while interview schedules were used for parents. 
Descriptive and inferential statistics were used to analyse quantitative data while qualitative data was managed through thematic techniques. The major finding indicated that parental SES and school involvement have powerful impact on children's academic achievement. It was recommended that schools should strengthen the collaboration between home and school in Westlands informal settlements. Contrary to the 2016 study, current qualitative study uses the ecological theory and focuses on how the SES of parents plays a role in the career development of their children with mild intellectual disabilities in an African context.

Kapinga's (2014) study aimed at assessing the impact of parental SES on students' academic achievement in secondary schools in Tanzania. The study employed a qualitative research approach informed by a case study research design. A purposively selected sample of 60 informants drawn from among parents, teachers and students was utilized. Data was collected through semi-structured interviews and focus group discussions and was thematically analysed. The study found that the majority of the students from the selected secondary schools were from low SES. A close relationship between SES and academic achievement was established. The study recommends among others that the government should review the policy of cost sharing and make if free to level students especially those of low SES. The current study instead uses semi-structured interviews to establish how the SES of parents plays a role in the career development of their children with mild intellectual disabilities.

Jamabo (2014 conducted a study to determine the influence of SES variables on adolescents' vocational aspirations in Nigeria. Stratified random sampling was used to select four schools from Port Harcourt Metropolis. A sample of 200 students (100 males and 100 females was used. Vocation interest inventory (VII) was used to collect data which was analysed using simple percentages and chi square. Findings revealed that parental SES has strong influence on adolescents' education. It was recommended that parents should encourage the development of a secure and enduring attachment relationship with their children. Contrary to the 2014 study, the current interpretive study focuses on how the SES of parents plays a role in the career development of children with mild intellectual disabilities.

\section{Methodology}

\subsection{Research Design and Site}

A phenomenological study design was used to examine lived experiences of parents in the career development of their children with mild intellectual disabilities (Creswell, 2014). The design was selected because it is best used in examining lived experiences and is normally used where there is little knowledge on a phenomenon (Donalek, 2004).The study was conducted at Tinashe Vocational Rehabilitation and Training Centre in Ndola, where children with mild intellectual disabilities from across the country, whose parents were the focus of the studyare offered skills training.

\subsection{Target Population, Sample Size and Sampling Procedure}

The population consisted of all parents whose children with mild intellectual disabilities were training at Tinashe Vocational, Rehabilitation and Training Centre in Ndola, Zambia. The sample comprised of 10 parents ( 5 males and 5 females) of children with mild intellectual disabilities.

\subsection{Research Instruments, Data Collection Procedures and Data Analysis}

The study used semi-structured interviews to collect data. These were deemed appropriate because interpretivist researchers favour to interact and dialogue with participants (Wahyumi, 2012). For triangulation purposes, parents of different education levels, occupation and SES were selected. Other sources such as documentary studies were consulted. Data was analysed thematically.

\subsection{Ethical Considerations}

Ethical considerations such as; seeking permission from the university ethical committee, respondents' confidentiality and other basic research conventions (Reinsk, 2018) were taken into consideration. All participants were given chance to consent their participation in the study and their identity was kept anonymous.

\subsection{Validity}


As a way to validate contents, the report was peer reviewed.

\section{FINDINGS AND DISCUSSION}

When asked on how their SES plays a role in career development of their children with mild intellectual disabilities, parents said it does so through role modelling and supporting their children in careers.

\section{(a) Role Modeling}

Seven of the ten parents said that their SES plays a role in the career development of their children with mild intellectual disabilities through role modeling. For example, parent M01 expressed his views:

Being educated and in formal employment, my financial status makes me a role model to my child. My status inspires him, makes him think of working and leading a better life of his own.

Being the first adults in the environment, parents are the first role models of their children with mild intellectual disabilities. As they interact with their children with mild intellectual disabilities on their SES, parents use themselves as examples. Through interactions, exemplifications and their availability in the environment, these parents avail working roles to their children thereby help them prepare them for future lives (Mathatha, 2013). For example, in the current study, parents with high levels of education and in formal employment indicated that they were of better SES meaning they were of admirable status to their children. This implies that such parents talked highly of how their education led them to being in occupations that gave them the SES they had. In turn, their children were inspired and their desire to be of some status also grew. By nature, parents are highly valued by their children more than any other person and this makes children depend and look to them. As noted by Nord (2012), such children with intellectual disabilities depend on their parents for almost everything. This means that the SES modelled by parents is what these children depend on to develop their careers. Therefore, this finding demonstrates that the higher the SES of parents, the higher the chances of children with mild intellectual disabilities developing careers.

Although parental SES plays a role in the career development of children with mild intellectual disabilities, some parents were too busy and unavailable to their children. Parent M05 said;

Although I am supposed to be a role model to my son, I am rarely at home because of the nature of my job (business). I know that this deprives him of the adult figure head he needs for his career development.

The absence of role models in the home environment means these homes lack the intellectual environment (of role models) needed for career development of children with mild intellectual disabilities. In this case, Microsystems of such children is negatively impacted by the low SES negatively impacting on career development of children.

In addition, the bio data of parents of children with mild intellectual disabilities in the current study indicate that most of them were of low SES and not role models to their children. Parent F06 had this to say;

Inemwandinshakwataimpiyabwinobwino, ndafilwaukwafwilishaumwanawandiumwaumengomoningafwailaukutiakaikalileku ntanshi. Bamulipililafyebamaseelebakukatolikaukufuma.... Nalishibaukutinshiliuwakupashanyamubumikalilekumwanawandi... nshamonapoabantuababangomwanawandiababombanokuikalila. Nangucingabefyo, nkonkafyeefyobakafundishabakwebaalanda. Ndamukoseleshafye. Limbi kutiaisasangakoifyakucita. (I am financially stressed, I fail to pay for my son or provide for him as I would want to... The catholic sisters pay for him .... I know he does not admire my socio-economic status.... I have not seen people of his condition working ... but I just go by what his former teachers said. .... I encourage him ... 
This finding demonstrates that the home environments such parents were impoverished of inspirable role models and it was unfit for career developmental of children with mild intellectual disabilities. This indicates that such parents are not inspirational to their children. It also shows how at risk such children are in their career development process. It should be noted that the low SES affects children differently through their impact on the behavior of parents towards their children. Consistently, Faisal (2014) argues that low socioeconomic families are often working all the time to take care of their families and have no time to be with their children.

The fact that most parents were of low SES is a clear demonstration that they were not role models to their children. This shows that the home environment constitutes the basic ecology where child development is learned, encouraged or suppressed (Dishion\& Patterson, 2006).

\section{(b) Supporting Children in Careers}

All the ten parents said their SES played a role in the career development of their children with mild intellectual disabilities through supporting their children in careers. However, the support parents gave their children differed as it bordered on their SES. It ranged from paying fees, providing basic needs and moral support. Parent M09 discussed:

Although he is on bursary, I am able to support my son with all basic needs. This support does not only motivate him but it also makes him think or realize that am supportive of what he is training in. In turn, he thinks of leading a better life in future.

M01 had this to say;

My SES allows me to help my child in his career development through support. I support give him for example, I pay for his fees and provide his groceries.

The variety of support given by parentsact as motivation to their children with mild intellectual disabilities in the career development process. Consistently,Klepfer's(2019) study showed that parental support motivates and encouraged children to work hard.It also helps create an everyday routine of taking up and developing certain careers. The finding of this study contrasts that of Cosgrove, Mckeown, Travers, Lysaght, NiBhrion and Archer, (2014) who found that parents of children with intellectual disabilities exhibited low support to their children. The moral support by some parents is an indication that irrespective of their low education and low SES they knew the importance of support in the career development of their children (Jamabo, 2014).

An analysis of the respondents indicate that some parents were of tertiary level of education. This resulted in them being in formal employment that offered good income and better SES which made them support their children. For example, parent F08 explained her experiences:

I am in formal employment and am able to provide for my daughter basic needs. This type of support boosts her morale to think of her future life as well. I know that the support I give her inspires her to think of working later...

Consistent with Kibera (2012), this finding demonstrates that education, occupation and income are indicators of SES. Education is one of the mostly used indicators of SES and is considered by many to be a canonical element of SES because of its influences on income and occupational status.

Although findings show that all parents said their SES played a role in their children's career development through different types of support, most parents did not sponsor their children in the careers they were pursuing due to their low SES. For example, M07 explained:

I am not in employment and am merely struggling, so it is really difficult to financially support my daughter the way I would want to. However, I encourage and morally support her in the career she is pursuing. I know this motivates her to think of working later....

This finding implies that homes of such parents were created out of economic strain and material hardship influencing their family functioning and in turn putting their children at risk of career development. It should be noted that support depends on the context in which parents find themselves 
in such as having resources. This finding is a demonstration that such parents provided very few, if any, stimulating experiences to foster the career development of their children. a recent study has shown that families with low SES often lack finances, social and educational support for their children (Gabriel et al. 2016) and children from homes of low SES have poor educational outcomes which negatively affect career development. The needs and demands remain unfulfilled and this negatively affects career development of their children. Research by Kapinga (2014) shows that low SES negatively and depressingly affects children's academic achievement due to high stress and tension it causes at home. Faisal (2014) argues that parents who fail to provide or support their children are considered to be capable of repressing and destroying the motivation and ability of their children. Given this disposition, it is understandable that the self-efficacy of children with mild intellectual disabilities with respect to career opportunities is linked to the economic support they receive from their parents. However, the works of Altman (1997) show how parents can play a facilitative role in confronting these barriers.

According to Kibera (2012), parents with fewer resources tend to feel less confident in supporting children especially those with disabilities. In addition, growing up in a low SES family is associated with high levels of perceived barriers to career attainment, lower levels of career related self-efficacy and lower expectations for educational attainment (ibid). According to Gabriel et al. (2016), poverty hampers career development and children from families of low financial resources are more likely to have difficulties in their career development. Poverty diminishes the capacity for supportive consistence and involved parenting which in turn diminishes the expression of affection and responsiveness.

It should be noted that children's ability to succeed in life depends on how successful parents manage their children in the home environment. Without parental approval (support), children are less willing to take up any career (Whiston\& Keller, 2008). This means that some children with mild intellectual disabilities in this study were deprived of the motivation (from support) they needed for career development. If not properly addressed, parental risk factors like limited financial resources and insufficient support, can have a significant influence on parental functioning and consequently on career development of children with mild intellectual disabilities. Consistent with the ecological theory used in this study, when parents, (a micro system for children), are impacted by the socioeconomic circumstances, their family functioning is negatively affected and in turn the career development of the children is inhibited.

Findings indicate that some parents had low expectations due tomild intellectual disabilities in their children. Parent F10 explained her experiences in ichi Bemba.
.... alandafyeatiakalabomba mu hotela limbi
Kwenanshilatininshininkishaukutiencitoakalabomba.
efyobamwebakusukulu. Namponganikwi...
Bakafundishabakweebengishibabwino.... (...he talks of working in a hotel... I am not clear what job really he will be doing, where he will be working and which hotel for now. His lecturers know better....).

Having a child who does not give back as expected may be traumatic to parents thereby rendering a bi-lateral feedback between parents and children very difficult. With low expectations, regardless of their financial status, parents may not be supportive of their children with mild intellectual disabilities (Gabriel et al. (2016). According to Kibera (2012), disability comes with challenges such as those of allocating funds for the care and training of their children with mild intellectual disabilities. Worse still, parents of lower income, hold values that place children with disabilities lowly and reflect less emphasis on occupational preparation (Cosgroove et al. 2014) as was the case in this study. This finding mirrors that Cosgrove et al. (2014) who found that parents of children with intellectual disabilities exhibited low occupational support due to low expectations.

It was also clear that some parents who did not sponsor their children had tertiary level of education and or in formal employment while others were in business. Parent M09 discussed:

Although my son is on bursary, .... I provide his basic needs... 
The Role of Parental SES in Career Development of Children with Mild Intellectual Disabilities at Tinashe Vocational Rehabilitation and Training Centre, Zambia.

The lack of support from such parents suggests that they did not want to spend into a "bottomless pit". It also demonstrates that some of these parents did not expect their children to progress into employment.

Furthermore, the finding it clearly indicates that negative attitudes on disabilities are still rooted in some parents. Concurrently, Kibera (2012) found that parents of children with disabilities tend to first direct resources to children without disabilities giving less hope and encouragement for further education to those with disabilities. Yet, effective parenting, good home climate and well perceived parental support facilitates career development of children (Faisal, 2014). Parents need to display positive attitudes to their children with mild intellectual disabilities if these children are to also have positive attitudes and career development. Recent research by Klepfer (2019) has shown that without parental support, children with intellectual disabilities fail to explore and learn from their parents negatively affecting development.

According to Muchalicek et al., 2015), support that parents offer depends on how neighbours and communities view intellectual disability. However, with negative attitudes still prevailing in Zambia (Nzala, 2016; Ndhlovu, 2010), children with mild intellectual disabilities may be at risk of receiving the best parental support. Therefore, parents should be made to understand Asbury's assertion that despite their challenges in performance, their children with mild intellectual disabilities can and do go on to succeed into employment. This calls for the need to sensitise parent on the matter.

\section{CONCLUSiON}

Although the SES of parents plays a role in the career development of children with mild intellectual disabilities, low parental expectations emanating from lack of knowledge on mild intellectual disability and its educational implications negatively influence family functioning. In turn, this negatively affects the career development of children with mild intellectual disabilities and exacerbates the already existing unemployment rates among such individuals.

\section{RECOMMENDATION}

Based on the findings, the study recommends that the Ministry of Higher Education, through the skill training institution, provides sensitizations or awareness to parents of children with mild intellectual disabilities on mild intellectual disabilities and its educational implications. In addition, the Skill Training Institutions should help form or strengthen Support Network Systems for parents of children with mild intellectual disabilities to help alleviate the challenges that come with having a child with mild intellectual disabilities.

\section{FUTURE RESEARCH}

It would be prudent for future research to consider the size of families to better understand how the SES of parents plays a role in the career development of children with mild intellectual disabilities.

\section{REFERENCES}

[1] Altman, J. H. (1997). "Career development in the context of family experiences." In Diversity and Women's Career Development: from Adolescence to Adulthood (Eds). Helen S. Farmer, 229-242. Thousand Oaks, CA: Sage.

[2] Bronfenbrenner, U. (1999). Ecology of the family as a context for human development. Research perspectives. Developmental Psychology, 22, 723-742.

[3] Cosgroove, I.C. Mckeown, J., Travers, Z., Lysaght, O., NiBhrion\& Archer, P. (2014). Educational experiences and outcomes on children with special education needs. A second analysis of data from the growing up Ireland study. Trim: NCSE.

[4] Creswell, J. (2014). Research design: Qualitative, quantitative and mixed methods approaches. Lincoln: Sage Publishers.

[5] Dishion, T.J. \& Patterson, G.R. (2006). The development and ecology of antisocial behaviour in children and adolescents. In Ciccheti, O. Cohen, D.J. (eds) Developmental Psychopathology, Vol 3, 503-541. Wiley Hoboken, NJ. USA.

[6] Donalek, J.G. (2004). Phenomenology as a qualitative research method. Urologic Nursing. Vol 24, (6), 516-517. 
The Role of Parental SES in Career Development of Children with Mild Intellectual Disabilities at Tinashe Vocational Rehabilitation and Training Centre, Zambia.

[7] Elshelman, A. (2013). SES and social class as predictors of career adaptability and educational aspirations in high school students. Southern lllinois University Carbandale. Open SIUC. http://opensiuc.lib.siu.edu/thesis

[8] Faisal, I.M. (2014). The influence of parental SES on their involvement at home. International Journal of Humanities and Social Sciences, Vol 4 (5), 146-154.

[9] Gabriel, M.N., Muasya, I., Mwangi, J., Makhungulu, M.J. \&Ewoi, L. (2016). The influence of parental SES, involvement in learning activities and its influence on children's academic performance in informal urban settlement in Westland Division, Nairobi County. International Journal of Education and Science, Vol 3 (2), 54-65.

[10] Jamabo, T. (201). Relationship between parental socioeconomic variables and adolescents' vocational aspirations. Journal of Education and Practice, Vol 5 (13), 169-172.

[11] Kapinga, S.O. (2014). The impact of parental SES on students' academic achievement in secondary schools in Tanzania. International Journal of Education, Vol 6 (4), 120-132

[12] Kerka, S. (2000). Parenting and career development. Erick Digest, 214.

[13] Kibera, L.W. (2012). Career aspirations and expectations of secondary school students of the 8-4-4 system of education in Kiambu, Kigiado and Machakos districts, Kenya. Unpublished Masters' Thesis, Kenyatta University.

[14] Mathatha, V. (2013). Career development of learners with visual impairments: A case of Lions and Magwero schools for the visually impaired.Unpublished. Masters' Dissertation. Lusaka: University of Zambia.

[15] Muchalicek, W., Lang, R. and Raulston, J.T. (2015). 'Training Parents of Children with Intellectual Disabilities: Trends, issues and future directions'. Curriculum Development Report, 2, 110-118.

[16] Ngozi, O.O. \&Eze, C.O. (2015). Parental SES as a predictor of vocational aspirations of secondary school students in Nigeria. Implications for peace curriculum planners and special educators. International Journal of Curriculum and instruction, 7 (2), 18-34.

[17] Ndhlovu, D. (2010). Life Conditions of Females with Mental Retardation: A case of graduatesfrom vocational training institutions. Unpublished PhD Thesis, University of Zambia, Lusaka.

[18] Nord, D. (2012). People with disabilities in America's work force: time for fresh thinking. Impact, Vol, $25,1$.

[19] Nzala, M.A. (2006). Parental Involvement in the Education of their Intellectually-challenged Children. A case of selected special units in Lusaka District. Unpublished Master's Dissertation, University of Zambia, Lusaka.

[20] Ramona, P. and Loredana, D. (2014). 'The Impact of the Family on the Career Choices of Adolescents'. Procedia Social and Behavioural Sciences, (2), 3407-3411.

[21] Reinsk, D. (2011). What is ethics in research and why is it important? New York: Oxford University Press.

[22] Roundy, 1. (2015). Bronfenbrenner's ecological system. www.citethisformcom/topic Visited August, 2017.

[23] Schultheiss, D.E.P., Kress, H.M., Manzi, A.J., \& Glasscock, M.J. (2001). Relational influences in career development: A qualitative inquiry. Counseling Psychologist, 29 (2), 214-239.

[24] Wahyuni, D., (2012). The research design maze: understanding paradigms, cases, methods and methodologies, Journal of Applied Management Accounting Research, Vol. 10, 1, 69-80.

[25] Whiston, S.C. (2008). The role of parental influences on young adolescents' career development. Journal of Career Assessment, 16, 198-217. 
The Role of Parental SES in Career Development of Children with Mild Intellectual Disabilities at Tinashe Vocational Rehabilitation and Training Centre, Zambia.

\section{AUTHORS' BIOGRAPHY}

Viola Mathatha, has 28 years of teaching experience. She taught at a secondary school for 20 years before moving to Kwame Nkrumah University where she worked for 4 years. Currently, she is a lecturer at Malcom Moffat College of Education in the Department of Education. She is currently pursuing her $\mathrm{PhD}$ in Special Education with the University of Zambia.

Dr. Daniel Ndhlovu holds a $\mathrm{PhD}$ (Special Education), has 37 years teaching experience and is formerly Assistant Dean, Post Graduate, School of Education, University of Zambia and formerly Director, Institute of Distance Education, University of Zambia. He is a lecturer in the School of Education, Department of Educational Psychology, Sociology and Special Education.

Citation: Mathatha Viola, Ndhlovu Daniel. "The Role of Parental SES in Career Development of Children with Mild Intellectual Disabilities at Tinashe Vocational Rehabilitation and Training Centre, Zambia." International Journal of Humanities Social Sciences and Education (IJHSSE), vol 7, no. 3, 2020, pp. 8-16. doi: http://dx.doi.org/10.20431/2349-0381.0703002.

Copyright: (C) 2020 Authors. This is an open-access article distributed under the terms of the Creative Commons Attribution License, which permits unrestricted use, distribution, and reproduction in any medium, provided the original author and source are credited. 